\title{
Stability Study of a Mixed Islanded Power Network
}

\author{
A.C. Padoan Jr., C. Nicolet, Member, IEEE, B. Kawkabani, Member, IEEE, J.-J. Simond, Member, IEEE, A. \\ Schwery, Member, IEEE, F. Avellan
}

\begin{abstract}
This paper presents the modeling, simulation and analysis of the dynamic behavior of a mixed power network of 2.78 GW including hydro, thermal and wind power plants. The modeling of each power plant is described. The set of parameters of the turbine speed governor of the hydroelectric power plant is determined with a specific identification procedure to achieve stable operation for different cases such as interconnected, isolated or islanded operation. The analysis of the stability of the entire mixed islanded power plant is investigated through time domain simulations for different sets of controllers parameters and for different disturbances (load rejection and turbulent wind speed profile).
\end{abstract}

Index Terms-Wind park, hydroelectric power station, power network, stability, identification

\section{INTRODUCTION}

$\mathbf{R}$ ENEWABLE energy sources like wind farms and hydroelectric power plants will play in the next coming years a more important role in the production of electricity. The stability study and analysis of the transient behavior of mixed power networks involving different types of energies such as hydro, thermal and wind power, become an important challenge for planners of such complex power networks.

The aim of the present study is to investigate the dynamic behavior of an islanded power network of $2.78 \mathrm{GW}$ presented in Fig. 1, featuring about $17 \%$ of wind power, $35 \%$ of hydropower and $47 \%$ of thermal power. It is well-known that the governor control characteristics of the hydroelectric units have a great importance to stabilize the network, and accurate turbines models are also very important for the controllers' parameters tuning [1] [2]. Therefore, the power system behavior is analyzed from the hydroelectric power plant point of view in order to determine the best control parameters set of the hydraulic turbine speed governor to guarantee the stability of the frequency of the mixed islanded power network.

In order to determine the control parameters of the hydroelectric power plant, an identif cation procedure is used in the present study. It consists of the determination of a discrete transfer function of the turbine. The input and output signals

This work was developped by the Laboratory for Hydraulic Machines and the Electrical Machinery Laboratory in the Swiss Federal Institute of Technology in Lausanne.

A.C. Padoan Jr. is with the ALSTOM (Brazil) Ltd., Sao Paulo-SP, Brasil.

A. Schwery is with the ALSTOM (Switzerland) Ltd., Hydro Generator Technology Center, CH-5242 Birr, Switzerland.

C. Nicolet is with Power Vision Engineering, Chemin des Champs-Courbes, CH-1024, Ecublens, Switzerland

B. Kawkabani and J-J. Simond are with the Laboratory of Electrical Machines of the Swiss Federal Institute of Technology, CH-1015 Lausanne, Switzerland.

F. Avellan is with the Laboratory for Hydraulic Machines of the Swiss Federal Institute of Technology, Av. de Cour 33Bis CH - 1007 Lausanne, Switzerland are respectively the guide vanes opening and the turbines speed. Two different input signals are employed: a pseudo random binary sequence (PRBS) is used to estimate highfrequency Bode diagram ( 0.5 to $20 \mathrm{~Hz}$ ), and a square-wave signal is used to estimate low frequency Bode diagram (0 to $0.5 \mathrm{~Hz}$ ). A similar process of identif cation was successfully implemented for a pump-storage unit [3]. This identif cation procedure has been applied for different cases of operation of the network: interconnected, isolated and islanded operation. For each case of operation, the corresponding turbine transfer functions are deduced and governor parameters determined.

The paper is organized as follows. First, the models of different power plants are presented in section II. The identif cation procedure is described in section III, and the results of identif cation of the governor parameters are presented in section IV. Finally, the performances of different sets of controllers' parameters are compared in section $\mathrm{V}$ through time domain simulations in the case of a load rejection and turbulent wind speed prof le.

\section{Modeling}

\section{A. Power network presentation}

Figure 1 presents the power network comprising a $1.3 G W$ thermal power plant, a $1.0 \mathrm{GW}$ hydroelectric power plant and a $480 M W$ wind farm. Table I presents three circuit breaker conf gurations. Each conf guration represents one mode of operation, as described below:

1) Interconnected operation: only the hydroelectric power plant is connected to an inf nite network;

2) Isolated operation: the hydroelectric power plant is connected to a passive consumer load;

3) Islanded operation: the three power plants are connected to a passive consumer load.

The transmission lines of $500 K V$ have the same parameters: $R=0.1 \Omega$ and $L=1 \mathrm{mH}$. The power network represented in Fig. 1 is simulated using the software package SIMSEN, developed for the simulation and the analysis of power systems [4], [5], [6]. The modeling of the 3 power plants are presented below.

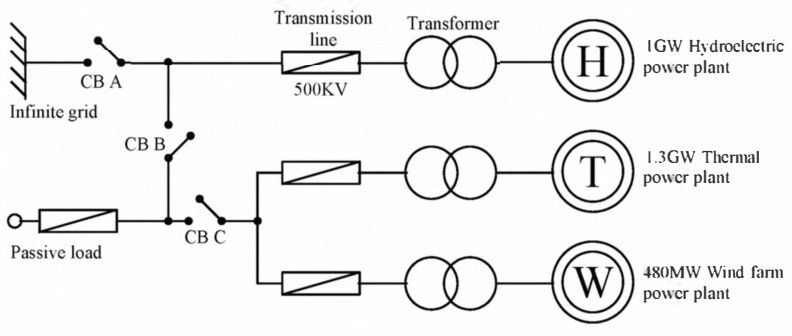

Fig. 1. Layout of the mixed power network. 
TABLE I

CiRCUIT BREA KERS CONFIGURATION.

\begin{tabular}{r|c|c|c} 
Operation & CB A & CB B & CB C \\
\hline Interconnected & ON & OFF & OFF \\
Isolated & OFF & ON & OFF \\
Islanded & OFF & ON & ON
\end{tabular}

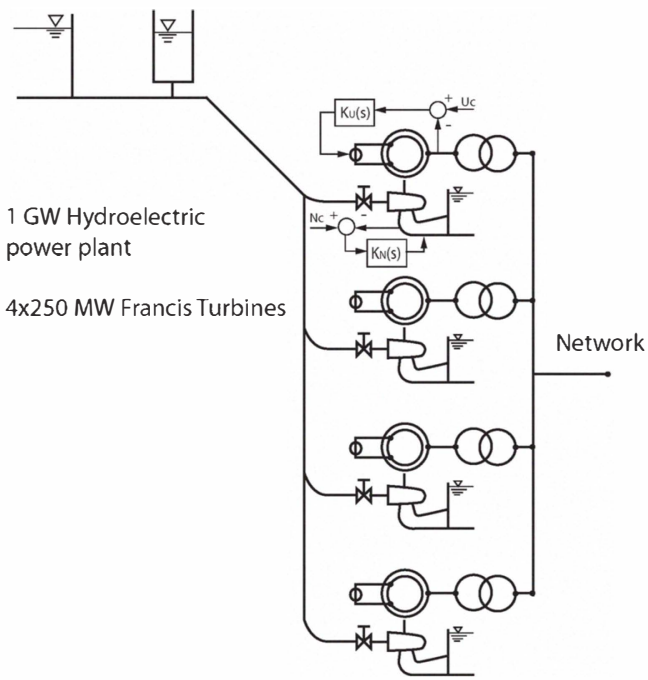

Fig. 2. Hydroelectric power plant layout.

\section{B. Hydroelectric power plant model}

1) Hydraulic circuit modeling: The hydraulic components are modeled in SIMSEN with an equivalent electric circuit, where pressure is analogue to voltage and discharge is analogue to current, leading to a T-shaped equivalent circuit diagram modeling an elementary hydraulic pipe. Based on this approach, other hydraulic components models such as pipes, valves, surge tanks and turbines are presented in [7] or [8]. The modeling of the hydaulic system enables taking into account water hammer, mass oscillation, and turbine characteristics effects.

2) Hydroelectric power plant model: The $1 G W$ hydroelectric power plant model of Fig. 2 is composed of four Francis turbines and four synchronous machines of $250 \mathrm{MVA}$ rated power each. The turbines are connected to the upstream dam through a $5 \mathrm{~km}$ gallery, a surge tank and a $1.1 \mathrm{~km}$ penstock. The maximum head is $315 \mathrm{~m}$. The turbines are modeled using the turbine characteristics $Q_{11}=Q_{11}\left(N_{11}\right)$ and $T_{11}=T_{11}\left(N_{11}\right)$ where $N_{11}, Q_{11}$ and $T_{11}$ are respectively the speed, discharge and torque factors, see [7]. The excitation system has a standard PID voltage regulator. Its model is based on the block diagram of the regulator UNITROL developed by ABB.

\section{Wind farm model}

1) Wind turbine model: A great variety of wind turbines architectures had been developed [9] [10] [11]. The architecture modeled in this work is a doubly fed induction generator, hereafter DFIG, with variable speed of $\pm 7 \%$ [12] [13]. The general diagram is presented in Fig. 3.

The general control structure of the DFIG is presented in Fig. 4. The main parameters of the wind turbine model are

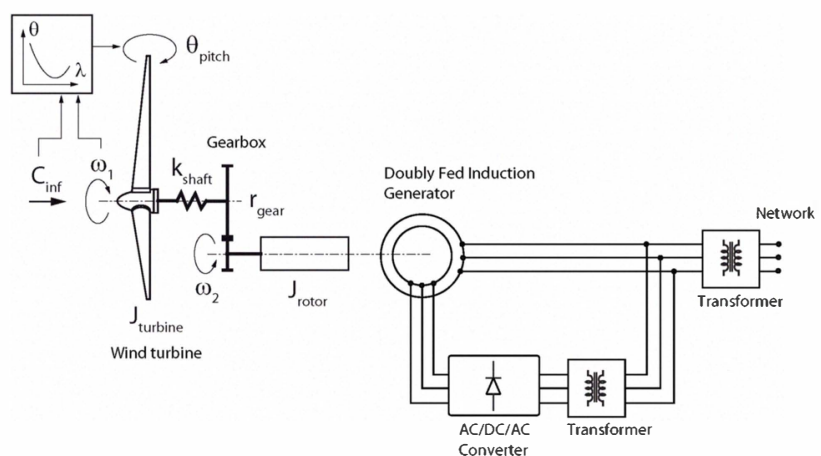

Fig. 3. Doubly fed induction generator diagram.

presented in Table II. More details about the DFIG architecture can be found in [14].

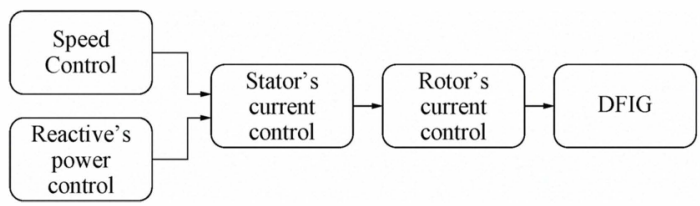

Fig. 4. Power converter control

The chosen control strategy optimizes the conversion of power by using a look-up table def ning the optimal turbine speed $n_{\text {set }}$ and the optimal pitch angle $\theta_{p, s e t}$, set according to the wind velocity. Moreover the rotational speed is selected in order to maximize the turbine power coeff cient.

Indeed, the mechanical power $P_{m}$ transmitted by the wind to the turbine is calculated as follows [11]:

$$
P_{m}=\frac{1}{2} \rho C_{p} C_{\infty}^{3} \frac{\pi D_{r e f}^{2}}{4}
$$

where $C_{p}$ is the power coeff cient, $C_{\infty}$ is the wind velocity, $D_{r e f}$ is the turbine diameter and $\rho$ is the density of the fuid. $C_{p}$ can be approximated using [11]:

$$
\begin{gathered}
C_{p}=\frac{1}{2}\left(\frac{116}{\lambda_{i}}-0.4 \theta_{p}-5\right) e^{\frac{-21}{\lambda_{i}}} \\
\frac{1}{\lambda_{i}}=\frac{1}{\lambda+0.08 \theta_{p}}-\frac{0.035}{\theta_{p}^{3}+1} \\
\lambda=\frac{\omega_{\text {turbine }} R_{\text {ref }}}{C_{\infty}}
\end{gathered}
$$

The power coeff cient $C_{p}$ is a function of the pitch angle $\theta_{p}$ and tip speed ratio $\lambda$, which is function of the turbine speed $\omega_{\text {turbine }}$ in $[\mathrm{rad} / \mathrm{s}]$. So, an optimal speed exists for a given wind velocity and pitch angle. The $C_{p}$ curves as a function of $\lambda$ and $\theta_{p}$ are presented in Fig. 5.

2) Wind farm aggregate model: The wind farm considered for this study is a collection of 96 wind turbines represented in Fig. 6.

In order to reduce the dimension of the global system equation set and thus, reducing computational effort, an aggregated model of the wind farm can be employed [15] [16]. It consists of one wind turbine equivalent model of the whole wind 


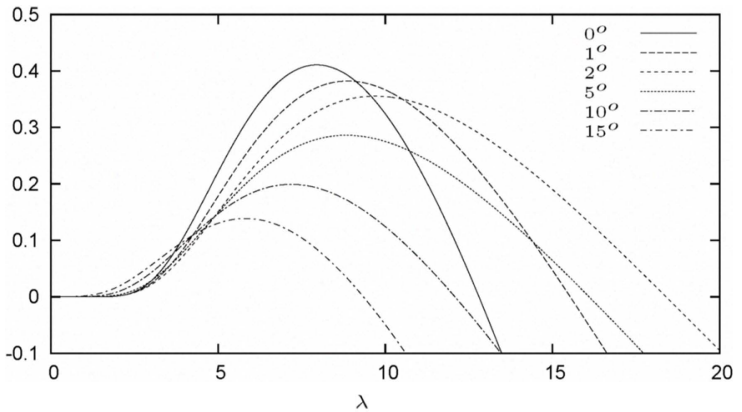

Fig. 5. Wind turbine characteristics.

TABLE II

WIND TURBINE PARAMETERS

\begin{tabular}{|l|l|}
\hline Turbine & \\
\hline \hline Rated rotational speed & $N_{n}=17 \mathrm{rpm}$ \\
\hline Rated power & $P_{n}=5 \mathrm{MW}$ \\
\hline Rated wind speed & $C_{n}=14 \mathrm{~m} / \mathrm{s}$ \\
\hline Referential diameter & $D_{r e f}=118.6 \mathrm{~m}$ \\
\hline Turbine inertia & $J=7.89 \cdot 10^{6} \mathrm{kgm}^{2}$ \\
\hline Torsional stiffness of shaft & $K=2.4 \cdot 10^{9} \mathrm{Nm} / \mathrm{rad}$ \\
\hline Viscous damping & $C=162050 \mathrm{Nms} / \mathrm{rad}$ \\
\hline Gear box ratio & $N_{g b}=19.6$ \\
\hline \hline DFIG machine & \\
\hline \hline Rated power & $S_{n}=5 \mathrm{MVA}$ \\
\hline Rated voltage & $U_{n s}=15.75 \mathrm{kV}$ \\
\hline Frequency & $F_{n}=50 \mathrm{~Hz}$ \\
\hline Winding ratio stator/rotor & $u=0.7917$ \\
\hline Pairs of poles & $P_{p}=9$ \\
\hline Rotor inertia & $J=162110 \mathrm{kgm}^{2}$ \\
\hline
\end{tabular}

farm. The total power of the equivalent turbine in this case is $P_{\text {total }}=96 \times 5 \mathrm{MW}=480 \mathrm{MW}$.

The electrical parameters are def ned in per unit, and thus are also valid for aggregate model.

3) Wind farm modeled with an array of aggregate models: The aggregate model imposes the same wind conditions to every turbine. As the area of a wind farm is large enough to expect an irregular distribution of the wind, it is necessary to modify the aggregate model to take into account the wind irregularity inside the wind farm. Two effects reinforce this assumption: (i) the park effect: the wind turbines placed close to each other are simultaneously shadowing each other; (ii) the wake effect: the turbulence produced by the blades of the wind turbine inducing a stronger turbulence on the last rows of turbines. One of the consequences is a difference in the total mechanical power transmitted to the wind farm. Another difference to be considered is the difference of potential energy accumulated in the shafts of each turbine [15].

In order to consider an irregular distribution of the wind, an array of aggregate models is used, as proposed by [15] and presented in Fig. 6. Thus, six aggregate models representing each row of the wind farm are simulated with different wind velocities. The wind velocity decreases $0.5 \mathrm{~m} / \mathrm{s}$ each time it passes through a row.

\section{Thermal power plant model}

The model of the $1.3 G W$ thermal power plant is based on steam $\mathrm{fux}$ and takes into account a constant pressure steam

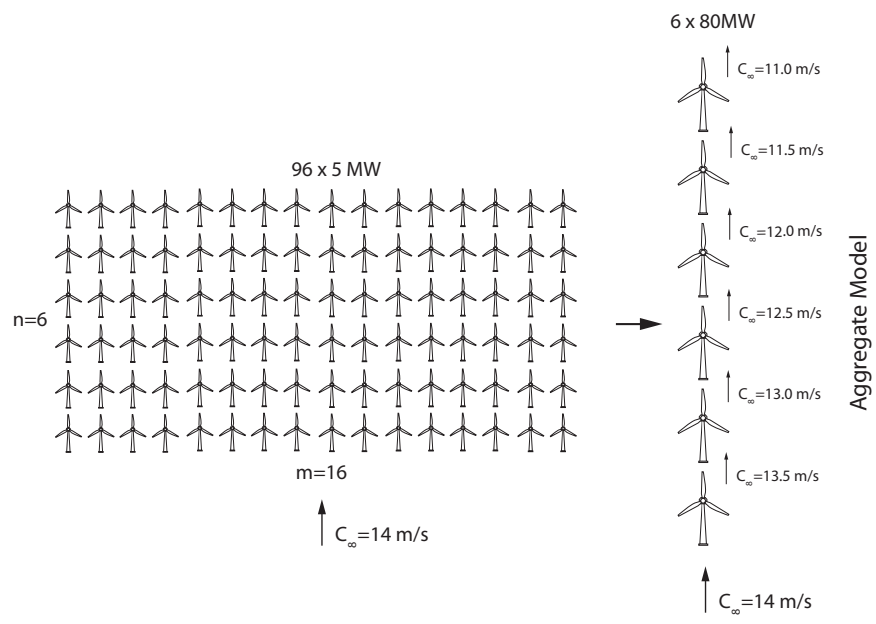

Fig. 6. Modeling of the wind farm using an array of aggregate models.

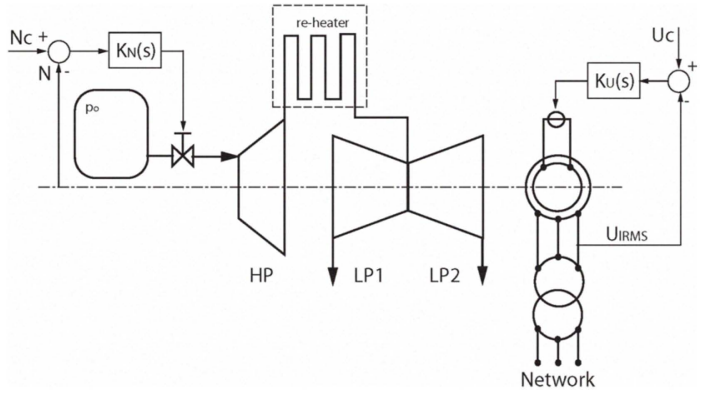

Fig. 7. Thermal power plant architecture

vessel, a regulating valve, a high pressure steam turbine, a reheater and two low pressure steam turbines as presented in Fig. 7 [17].

\section{IDENTIFICATION PROCEDURE}

In order to select the appropriate hydraulic turbine speed governor parameters, it is necessary to deduce the turbine transfer function. The hydraulic turbine transfer function is calculated as the ratio of the discrete Fourier transform of the turbine's speed $N_{k}$ and discrete Fourier transform of the guide vane opening $Y_{k}$.

Samples with period $\tau$ of the continuous time signals $y$ and $n$ obtained by a time domain simulation are considered for the discrete Fourier transforms. Two different sets of inputs are used. First, a pseudo random binary sequence is used to estimate the system's high frequency response for frequency range of 0.5 to $20 \mathrm{~Hz}$. For low frequencies, below $0.5 \mathrm{~Hz}$, a square wave input with a 2000 s period is used. The reason for using a square wave input is to avoid prohibitive simulation time required to properly estimate the transfer function for low frequencies using a PRBS input. Figure 8 presents the general process.

\section{FREQuenCy DOMAIN ANALYSis}

One of the targets of this study is to characterize the power network as seen from the hydro turbine. The identif cation of the transfer function for different operation modes aims 


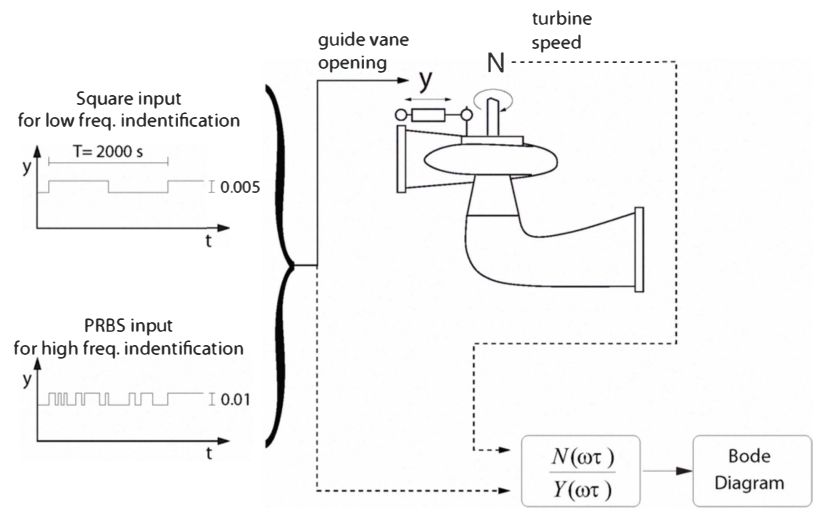

Fig. 8. Identif cation process

TABLE III

INITIAL CONDITIONS AND SET POINTS.

\begin{tabular}{|l|l|}
\hline Hydroelectric power plant initial active power & $P=0.6 \mathrm{pu}$ \\
\hline Thermal power plant active power reference & $P=0.85 \mathrm{pu}$ \\
\hline Wind speed & $C_{\infty}=14 \mathrm{~m} / \mathrm{s}$ \\
\hline Wind farm reactive power set point & $Q=0 \mathrm{p} . u$. \\
\hline
\end{tabular}

to evidence that in islanded operation, the system behaves differently from the other modes of operation.

One of the classical approaches is to use a set of parameters of the turbine governor dimensioned for isolated operation ${ }^{1}$. The other approach realized in this study consists of the design of optimized set of parameters of the turbine governor for islanded operation. Thus, when the network starts operating in islanded mode (being disconnected from a larger grid), the turbine governor parameters is adapted to improve the system stability.

To demonstrate the differences in each mode of operation, the Bode diagrams of the turbine transfer function are calculated for interconnected operation, isolated operation and islanded operation. Table III summarizes the initial conditions and references used for the identif cation of these transfer functions. During the procedure the wind velocity is kept constant and equal to $14 \mathrm{~m} / \mathrm{s}$.

\section{A. Hydroelectric power plant in interconnected operation}

The Bode diagram of the hydraulic turbine transfer function is presented in Fig. 9 for low frequencies: $0 \mathrm{~Hz}$ to $0.5 \mathrm{~Hz}$. It is possible to note that the gain is very low, which evidences the stabilizing effect of the inf nite power network for low frequencies. It means that variations of the guide vane opening has no effect on the turbine rotational speed. Nevertheless, the f rst natural frequency of the piping system is also visible on this transfer function.

\section{B. Hydroelectric power plant in isolated operation}

The Bode diagram for low frequency of the hydraulic turbine transfer function is presented in Fig. 10. Differently, in this case the DC gain is close to $25 \mathrm{~dB}$. Moreover, the natural frequencies related with hydraulic system dynamics appear, i.e., the mass oscillation mode and the penstock mode, [8].

\footnotetext{
${ }^{1}$ Most governors of hydroelectric generators are tuned to be able to govern isolated loads [18].
}
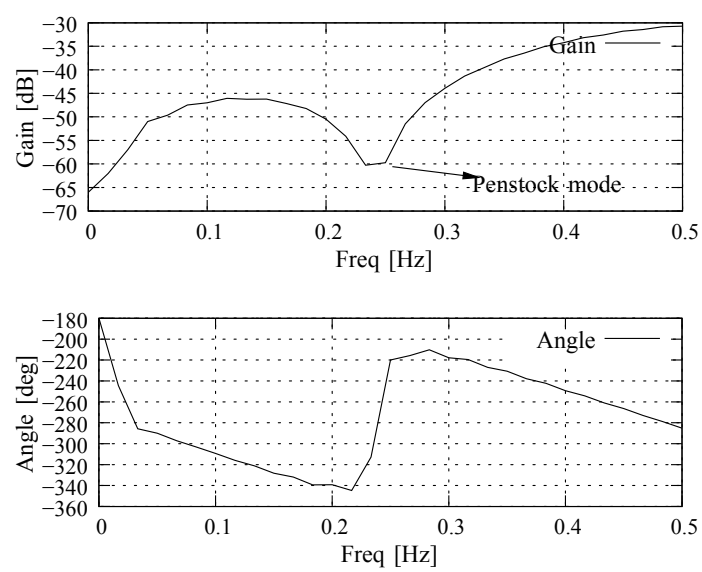

Fig. 9. Bode diagram of the hydraulic turbine transfer function in interconnected operation.
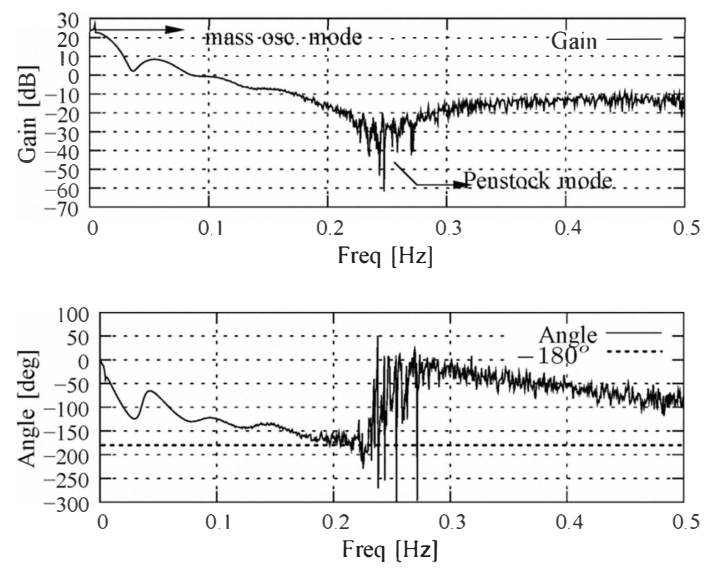

Fig. 10. Bode diagram of the hydraulic turbine transfer function in isolated operation.

\section{Hydroelectric power plant in islanded operation}

Figure 11 presents the Bode diagram of the hydraulic turbine transfer function for low frequencies in islanded operation. The main difference with the isolated and interconnected operation is a resonant peak that appears for the same frequency as the closed-loop thermal power plant mode ${ }^{2}$. The thermal power plant has a clear inf uence on the hydraulic turbine dynamics which can eventually bring the system to instability if an inappropriate set of parameters of the turbine governor is chosen. The high frequency Bode diagram of the turbine transfer function estimated using the PRBS signal is presented in Fig. 12, where the torsional shaft modes appear [8]. The other network conf gurations have similar results in this frequency range.

\section{Turbine Governor}

The hydraulic turbine governor architecture including servomotor model is presented in Fig. 13. The governor is a PID in series with power and speed control loops. The results of the previous section and the governor's transfer function are used

\footnotetext{
${ }^{2}$ This mode can be visualized after a load rejection, when the thermal power plant is connected in isolated operation.
} 

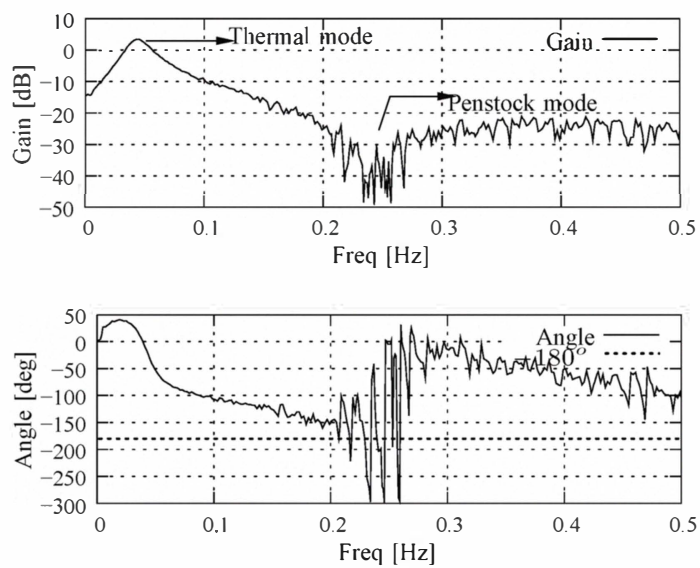

Fig. 11. Bode diagram of the hydraulic turbine transfer function in islanded operation.
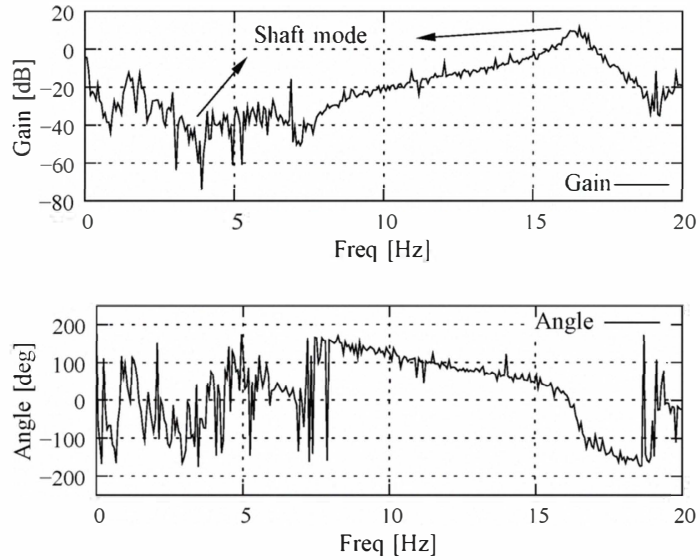

Fig. 12. Bode diagram of the hydraulic turbine transfer function in islanded operation for high frequencies.

to design three turbine governors. The governor' parameters can be adjusted in order to achieve an open-loop frequency response with a desired stability criteria and performance. The set of parameters of the three turbine governors are presented in Table IV. Each set of parameters is described as follows:

1) The frst set of parameters related to a classical design def nes a governor that imposes $60^{\circ}$ of phase margin to the system in isolated operation. The Bode diagram of the governor transfer function in series with the islanded operation system is presented in Fig. 14. It represents the controlled open-loop system. This governor is employed in islanded operation in order to guarantee full-stability.

2) The second set of parameters is selected in order to show an instable behavior due to the interaction between the thermal and hydroelectric power plants as presented in Fig. 15. This example demonstrates the risk for using a not properly designed set of parameters. In this case, the gain in the range near $0.05 \mathrm{~Hz}$ would appear lower and the instability could be unpredictable.

3) The third set def nes a governor optimized for islanded operation, imposing also a $60^{\circ}$ of phase margin, as presented in Fig. 16. This governor is tuned also to minimize the inf uence of the thermal power plant mode.

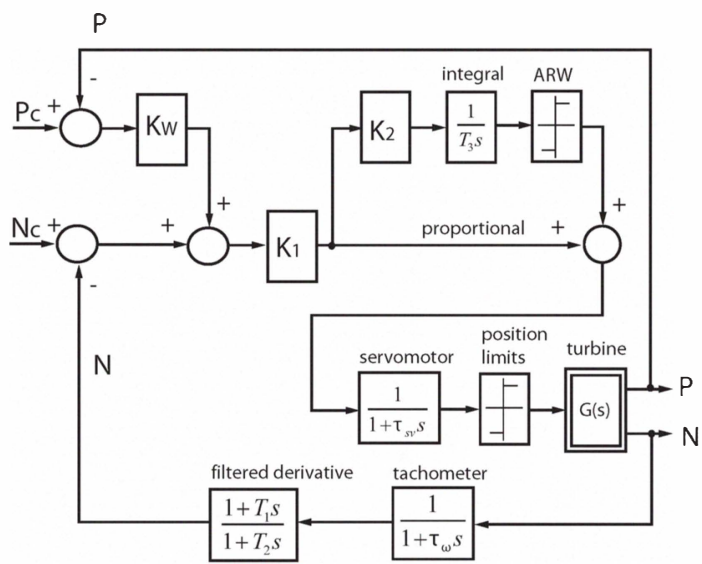

Fig. 13. Hydraulic turbine governor and servomotor model architecture
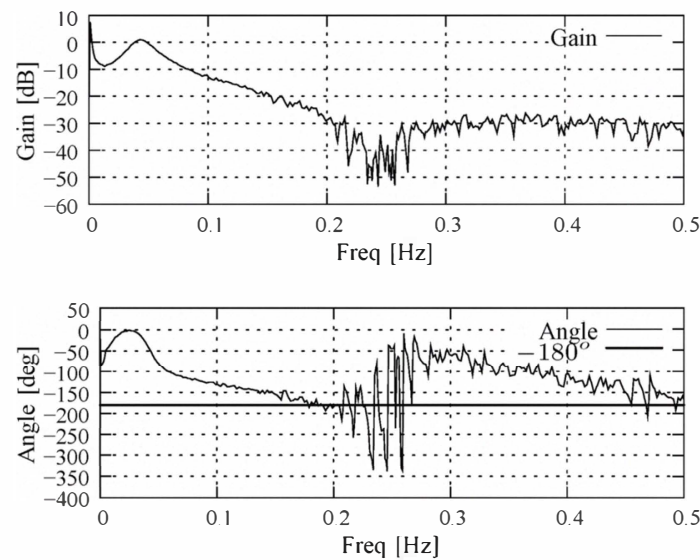

Fig. 14. Bode diagram of the hydraulic turbine transfer function in islanded operation system in series with the frst tubine governor.

Note that there are no general rules for tuning a turbine governor in islanded operation since each power system has its own peculiarities.

\section{TIME DOMAIN ANALYSIS}

The case of hydroelectric power plant in islanded operation is used to perform two time domain simulations. First, the
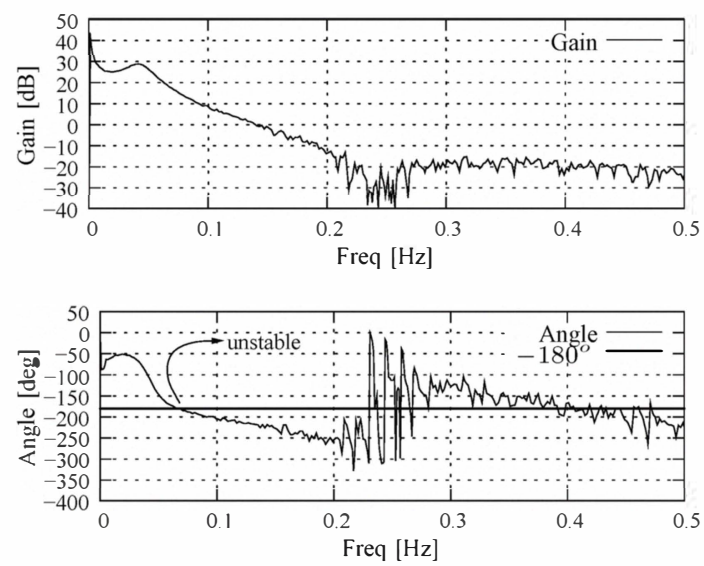

Fig. 15. Bode diagram of the hydraulic turbine transfer function in islanded operation system in series with the second tubine governor. 

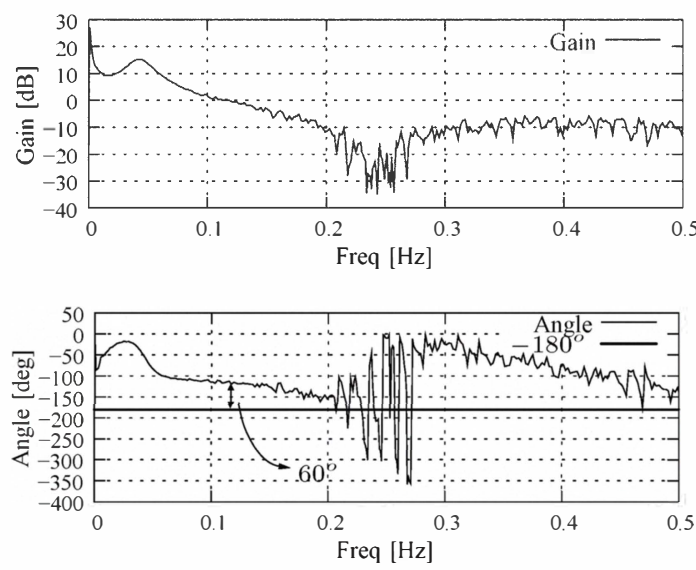

Fig. 16. Bode diagram of the hydraulic turbine transfer function in islanded operation system in series with the third tubine governor.

TABLE IV

TURBINE GOVERNOR PARAMETERS

\begin{tabular}{l|cccccccc} 
Set & $K_{1}$ & $K_{2}$ & $T_{1}$ & $T_{2}$ & $T_{3}$ & $K_{w}$ & $\tau_{s v}$ & $\tau_{w}$ \\
\hline 1 & 0.7 & 1 & 0 & 0 & 9 & 0 & 0.1 & 0.33 \\
2 & 1.0 & 1 & 0 & 0 & 0.2 & 0 & 0.1 & 0.33 \\
3 & 1.2 & 1 & 3.18 & 0.318 & 1.6 & 0 & 0.1 & 0.33
\end{tabular}

three turbine governor parameter sets are compared in the case of a load rejection considering the wind velocity constant and equal to $14 \mathrm{~m} / \mathrm{s}$.

The second investigation compares the frst and the third governors when a turbulent wind is introduced.

\section{A. Load rejection}

Using the same initial conditions presented in Table III, a $20 \%$ load rejection is simulated in the case of islanded operation.

The hydraulic turbine response is presented in Fig. 17, where $n$ is the turbine speed, $h$ is the head in the turbine, $y$ is the guide vane opening $(y \in[0,1])$ and $q$ is the discharge. All values are in per unit. One can notice that, as expected, the frst and the third governors are stable, while the second governor is unstable.

Figure 18 presents the time evolution of the load voltage frequency, see Fig. 18(a) and of the voltage RMS value, see Fig. 18(b). One can notice that the third governor exhibits better performance for both, frequency and voltage. Even if the turbine governor does not have a direct inf uence on the voltage control, it introduces a benef cial effect. One important point is that the thermal mode is attenuated with the third governor. The settling times of frequency and voltage are improved as well.

\section{B. Turbulent Wind}

A turbulent wind velocity prof le is created, using the wind model described in [19]. Figure 19 presents the wind velocity time evolution. Figure 20 compares the turbine's performance using the frst and third turbine governors. The third governor provides smallest frequency deviation than the frst governor, see Fig. 21. However, the third governor solicits the hydraulic

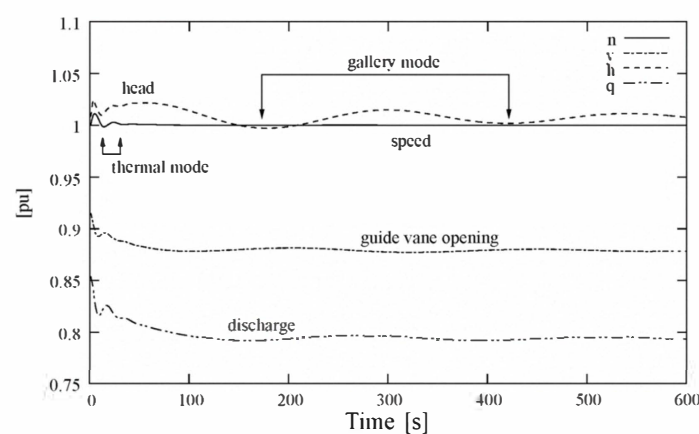

(a)

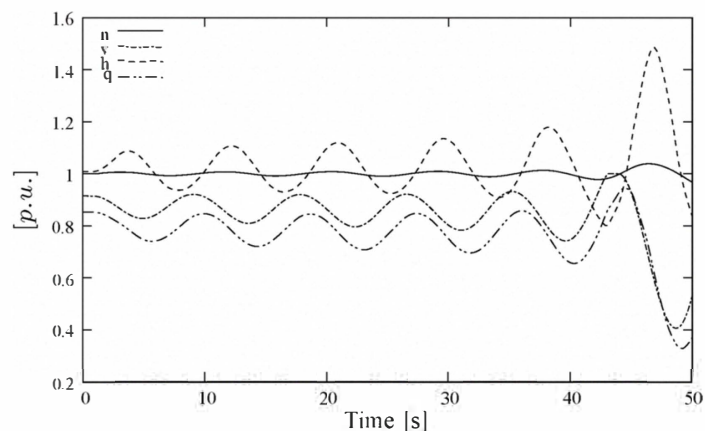

(b)

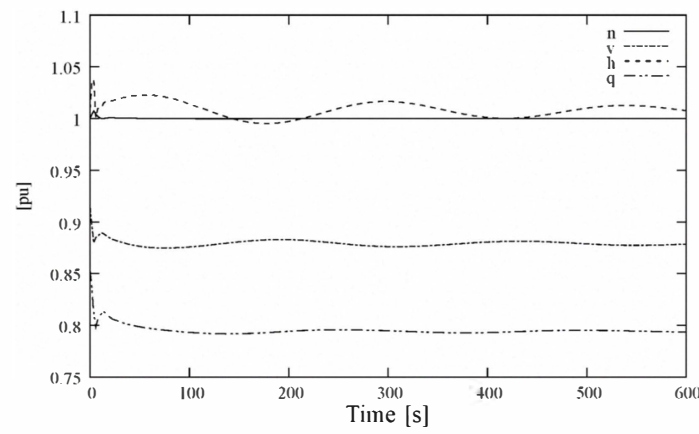

(c)

Fig. 17. Load rejection results for (a) the frst set of parameters (b) the second set and (c) the third set.

turbine more intensively. Indeed, the guide vane opening $y$, the head $h$ and the charge $q$ feature larger variations than using the $\mathrm{f}$ rst governor. In the case of governor $n^{\circ} 3$, the hydraulic turbine power control devices, i.e. servomotors, guide vanes and bearings, have higher solicitations. Since the islanded operation mode can be considered as a temporary situation, these strong solicitations are not applied in normal operation.

The third governor performances are presented in Fig. 22, where the total power being consumed and the power delivered by each power plant are represented as function of time. The hydroelectric power plant is the principal supplier of energy compensating the wind power fuctuations. This supplementary power is coming from the inertial masses of the hydro generators and from the turbine governor action. It is interesting to note that the $3 \mathrm{~Hz}$ shaft mode of the wind turbine appears in the power curves. This behaviour is explained by the strong coupling between the speed and the electric parameters in the induction generator [15]. 


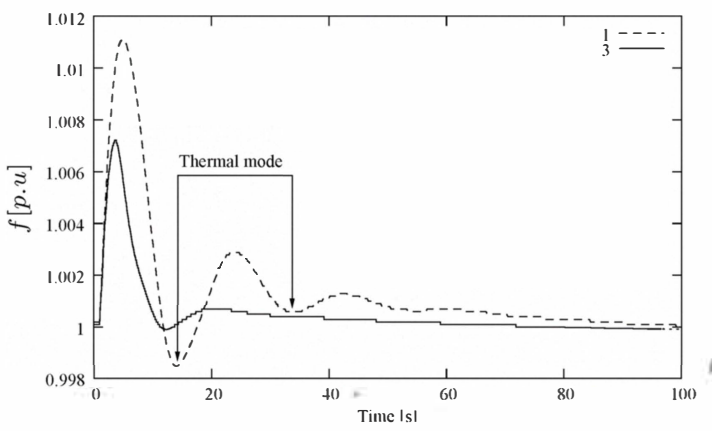

(a)

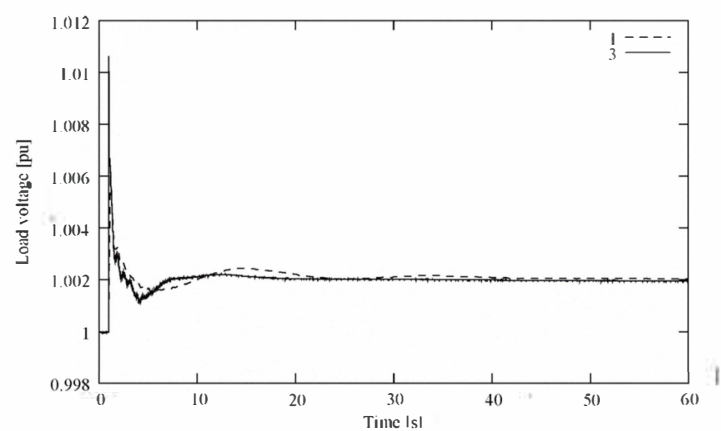

(b)

Fig. 18. Time evolution of (a) the frequency and (b) the load voltage resulting from load rejection.

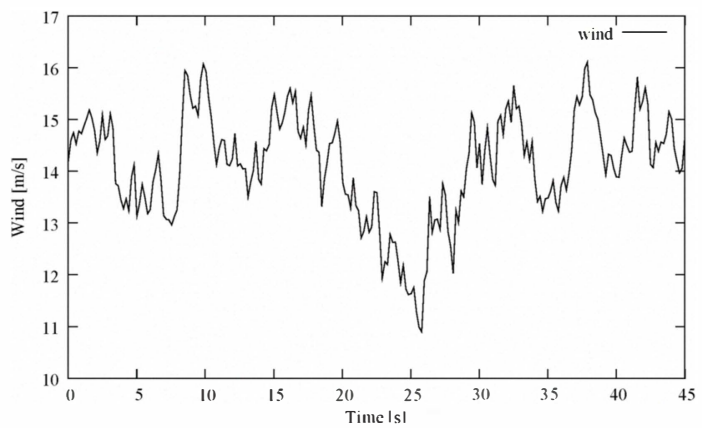

Fig. 19. Turbulent wind profle.

\section{CONCLUSION}

This paper presents the modeling, simulation and analysis of the dynamic behavior of a mixed islanded power network including hydro, thermal and wind power plants of total capacity of $2.78 \mathrm{GW}$. The analysis is performed in order to select the best control parameters set of the hydroelectric power plant in order to achieve the highest stability of the network frequency. The analysis of the hydraulic turbine transfer function for interconnected, islanded and isolated production modes points out:

- in interconnected operation, the hydraulic turbine operation benef ts from high stabilization effects for low frequencies from the connection to the grid;

- in isolated operation, the stability of the hydraulic turbine depends mainly on the hydraulic system dynamics, i.e. mass oscillation, water hammer, turbine characteristics, see also [7];

- in islanded operation, the stability of the hydraulic turbine

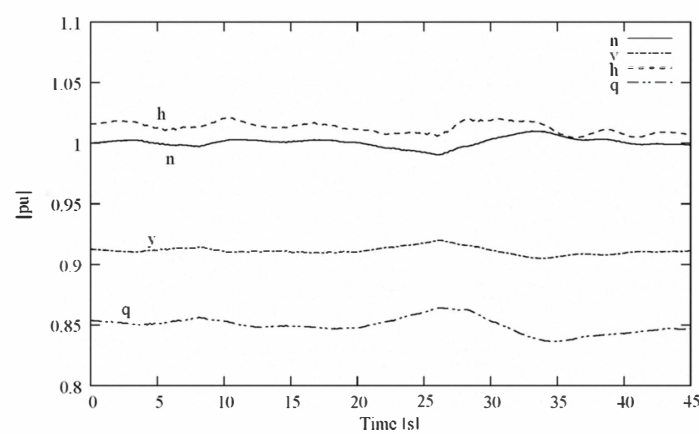

(a)

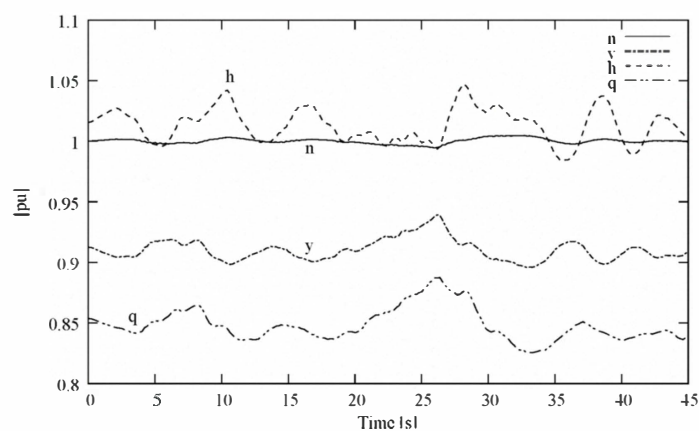

(b)

Fig. 20. Simulations results with turbulent wind obtained with (a) the frst turbine governor and, (b) for the third turbine governor.

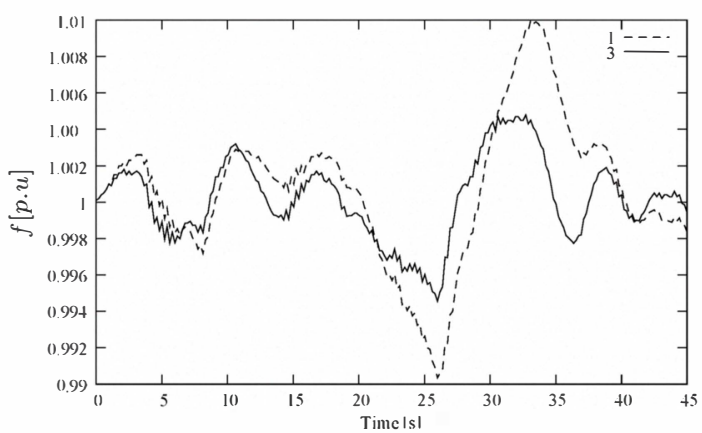

Fig. 21. Simulations results with turbulent wind obtained with the governor $n^{o} 1$ and $n^{\circ} 3$ for the load frequency.

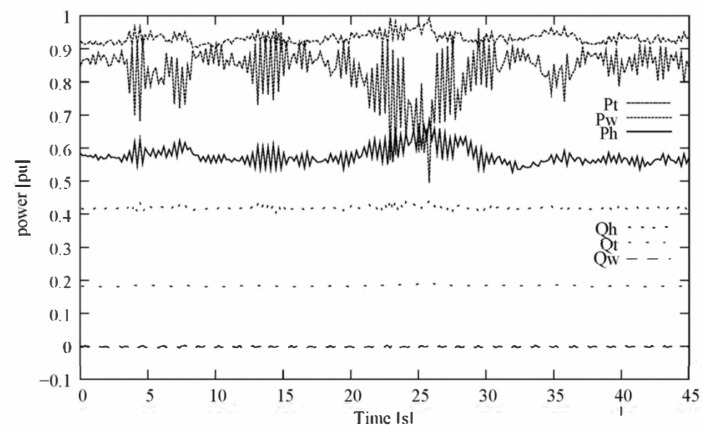

Fig. 22. Time evolution of the power produced by each power plant, with the third turbine governor. 
is largely inf uenced by the other productions sites; in our test case, the thermal power plant dynamics restricts the performances of the turbine speed governor.

The determination of the hydraulic turbine transfer function considering interconnected, isolated and islanded operation appears to be a very eff cient tool to set properly the parameters of the turbine speed governor according to the power network dynamics.

\section{REFERENCES}

[1] Working group on Prime Mover and Energy Supply Models for System Dynamic Performance Studies, "Hydraulic turbine control models for system dynamic studies," Power Systems, IEEE trans., vol. 7, no. 1, feb. 1992.

[2] P. Kundur, Power System Stability and Control. McGraw-Hill, 1993.

[3] D. Trudnowski and J. Agee, "Identifying a hydraulic-turbine model from measured f eld data," Energy Conversion, IEEE Transactions on, vol. 10, no. 4, pp. 768-772, December 1995.

[4] B. Kawkabani, Y. Pannatier, and J.-J. Simond, "Modeling and transient simulation of unif ed power fow controllers (upfc) in power system studies," Proceedings. IEEE Power Tech, 2007., pp. 333-338, Jul. 2007.

[5] A. C. Padoan Jr. , B. Kawkabani, A. Schwery, C. Ramirez, C. Nicolet, J.-J. Simond, and F. Avellan, "Dynamical behavior comparison between variable speed and synchronous machines with pss," IEEE Transactions on Power Systems, vol. 25, pp. 1555-1565, 2010.

[6] Y. Pannatier, B. Kawkabani, C. Nicolet, J.-J. Simond, A. Schwery, and P. Allenbach, "Investigation of control strategies for variable-speed pump-turbine units by using a simplif ed model of the converters," IEEE Transactions on Industrial Electronics, vol. 57, pp. 3039-3049, 2010.

[7] C. Nicolet, B. Greiveldinger, J. Hérou, B. Kawkabani, P. Allenbach, J. Simond, and F. Avellan, "High-order modeling of hydraulic power plant in islanded power network," Power Systems, IEEE Transactions on, vol. 22, no. 4, pp. 1870-1880, November 2007.

[8] C. Nicolet, "Hydroacoustic modelling and numerical simulation of unsteady operation of hydroelectric systems," Ph.D. dissertation, École Polytechnique Fédérale de Lausanne, 2007, thesis EPFL no 3751 downloaded at http://library.epf $. c h /$ theses/?nr=3751.

[9] G. Lalor, A. Mullane, and M. O'Malley, "Frequency control and wind turbine technologies," IEEE Transactions on Power Systems, vol. 20, pp. 1905-1913, Nov. 2005

[10] L. Hansen, P. Madsen, F. Blaabjerg, H. Christensen, U. Lindhard, and $\mathrm{K}$. Eskildsen, "Generators and power electronics technology for wind turbines," IECON '01. The 27th Annual Conference of the IEEE Industrial Electronics Society, 2001., vol. 3, pp. 2000-2005, Dec. 2001.

[11] S. Heier, Grid Integretaion of Wind Energy Conversion System. Wiley, 1998.

[12] J. Slootweg, H. Polinder, and W. Kling, "Dynamic modelling of a wind turbine with doubly fed induction generator," IEEE Power Engineering Society Summer Meeting, 2001., vol. 1, pp. 644-649, Jul. 2001

[13] Y. Lei, A. Mullane, G. Lightbody, and R. Yacamini, "Modeling of the wind turbine with a doubly fed induction generator for grid integration studies," IEEE Transactions on Energy Conversion, vol. 21, pp. 257264, Mar. 2006.

[14] A. Hodder, "Double-fed asynchronous motor-generator equipped with a 3-level VSI cascade," Ph.D. dissertation, École Polytechnique Fédérale de Lausanne, 2004, thesis EPFL no 2939 downloaded at http://library.epf .ch/theses/?nr=2939.

[15] V. Akhmatov and H. Knudsen, "An aggregate model of a grid-connected, large-scale, offshore wind farm for power stability investigations importance of windmill mechanical system," International Journal of Electrical Power and Energy Systems, vol. 24, pp. 709-717, Nov. 2002.

[16] C. Nicolet, Y. Vaillant, B. Kawkabani, P. Allenbach, J. Simond, and F. Avellan, "Pumped storage units to stabilize mixed islanded power network: a transient analysis," HYDRO 2008 Conference, Progressing World Hydro Development, Ljubljana, Slovenia, October 6-8 2008.

[17] A. Bolcs, Turbomachines thermiques. LTT/EPFL, 1993, vol. 1.

[18] IEEE Power Engineering Society, "IEEE Guide for the Application of Turbine Governing Systems for Hydroelectric Generating Units," IEEE Std 1207, 2004.

[19] J. Slootweg, S. de Haan, H. Polinder, and W. K. W.L., "General model for representing variable speed wind turbines in power system dynamics simulations," Power Systems, IEEE Transactions on, vol. 18, no. 1, pp. 144-151, Febuary 2003

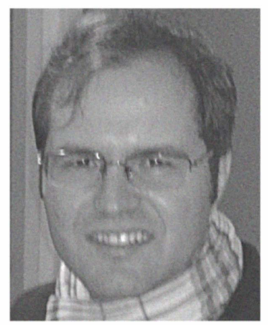

Antonio C. Padoan Jr. received in 2003 the B.Eng. degree from the Escola de Engenharia de Sao Carlos (USP), Sao Carlos, Brazil, and the M.S. degree in electrical engineering in 2005 from the Laboratory of Intelligent Systems (LASI) in the same School. $\mathrm{He}$ also received the M.S. degree in mechanical engineering in 2008 from the Laboratory for Hydraulic Machines of the École polytechnique fédérale de Lausanne (EPFL), Lausanne, Switzerland. He joined Alstom Hydro Power Ltd., Sao Paulo, Brazil, in 2005

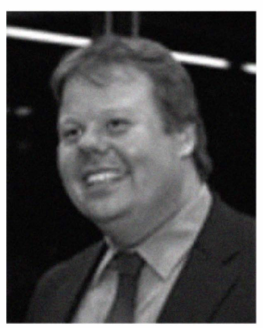

Christophe Nicolet (M'08) received the M.S. degree in mechanical engineering and the Ph.D. degree from the École polytechnique fédérale de Lausanne (EPFL), Lausanne, Switzerland, in 2001 and 2007 , respectively. Since then, he has been the Managing Director and the Principal Consultant of Power Vision Engineering, Lausanne. He is also a Lecturer at EPFL in the feld of Flow Transients in systems.

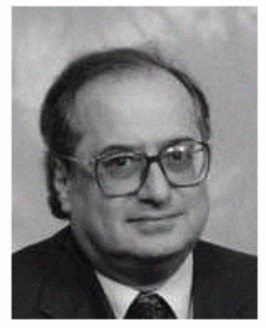

Basile Kawkabani (M'00) received the M.S. degree in 1978 from the Ecole Supérieure d'Electricite (Supélec), Paris, France, in 1978, and the Ph.D. degree from the École Polytechnique Fédérale de Lausanne, Lausanne, Switzerland, in 1984. Since 1990, he has been a Lecturer and a Senior Researcher in the Laboratory of Electrical Machines, École Polytechnique Fédérale de Lausanne, Lausanne. His interests include modelling of power systems, power system stability and control.

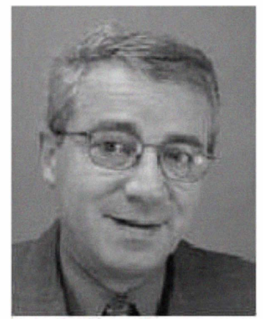

Jean-Jacques Simond (M'00) received the M.S degree in electrical engineering and the Ph.D. degree from the École Polytechnique Fédérale de Lausanne Lausanne, Switzerland, in 1967 and 1976 respectively. Until 1990, he was with $\mathrm{BBC} / \mathrm{ABB}$, f rst as $R \& D$ engineer and later as the Head of the technical department for hydro and diesel generators. Since 1990, he has been a Professor and the Director of the Laboratory of Electrical Machines, École Polytechnique Fédérale de Lausanne, Lausanne. He is also a Consultant to various international electrical machines manufacturers and utilities.

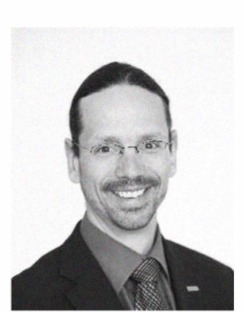

Alexander Schwery (M'04) received received the M.S. degree in electrical engineering and the Ph.D. degree from the École Polytechnique Fédérale de Lausanne, Lausanne, Switzerland, in 1994 and 1999 respectively. In 1999, he joined ALSTOM (Switzerland) Ltd., Birr, Switzerland, where his main felds of application are the use and development of different simulation and calculation tools for salient-pole generators. He is currently the Head of the Electrical Group, Hydro Generator Technology Center.

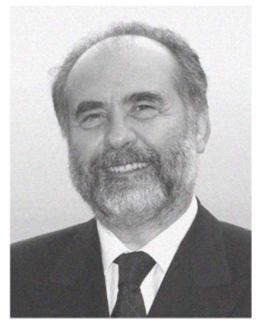

Francois Avellan received the M.S. degree in hydraulic engineering from INPG, Ecole Nationale Supérieure d'Hydraulique, Grenoble, France, in 1977 and, in 1980, received the Ph.D. degree in engineering from the University of Aix-Marseille II. France. He was a Research associate at the École Polytechnique Fédérale de Lausanne, Lausanne, Switzerland, in 1980, has been the Director of the Laboratory for Hydraulic Machines since 1994, and was appointed Ordinary Professor in 2003. Prof F. Avellan is the Chairman of the IAHR Section on Hydraulic Machinery and Systems. 